\section{Projeto Meninos do Rio: mundo da vida, adolescência e riscos de saúde}

\author{
The Meninos do Rio Program: \\ lifeworld, adolescence, and health risks
}

\begin{abstract}
This study focuses on health risks among teenagers from two towns in the São Francisco River Valley (Ibiaí and Morada Nova) and slums in Morro das Pedras, Belo Horizonte, Minas Gerais State, Brazil. The study discusses teaching and extracurricular activities by the Federal University in Minas Gerais in these localities, aimed at promoting health in adolescence. The authors use the Habermas communicative action theory as the main theoretical and methodological approach. The research adopted a qualitative and quantitative methodology, including dynamic observation, focus groups, interviews, and questionnaires answered by high school students. Sexuality, work, and violence were the main themes and were associated with numerous health risks. Work in the 10-to-14year-old group was associated with nearly all types of health risks. The authors analyze the relations between context and adolescent behavior using the Habermasian concept of lifeworld colonization.
\end{abstract}

Adolescent; Health Promotion; Adolescent Behavior
Elza Machado de Melo 1

Horácio Pereira de Faria 1

Maria Aparecida Machado de Melo 2

Adriana Braga Chaves 1

Graziela Paronetto Machado 1

\title{
Apresentação
}

O Projeto Meninos do Rio, nome dado em alusão ao Rio São Francisco, região onde teve início, é constituído por um amplo leque de atuação e engloba as nossas intervenções relativas à adolescência, com base na nossa prática universitária extramuros de ensino, extensão e pesquisa. No que se refere à pesquisa o objetivo é investigar os riscos à saúde dos adolescentes e seus determinantes, em algumas cidades do Vale do Rio São Francisco e em um aglomerado urbano de Belo Horizonte, Minas Gerais, Brasil - o Morro das Pedras -, valendo-se de um estudo descritivo associado a um estudo qualitativo que busca fazer as correlações daqueles riscos com as determinações sócio-econômico-político-culturais e destas com as interpretações e os significados contextualmente produzidos. Este trabalho apresenta os resultados produzidos no primeiro ano de inserção naquelas realidades estudadas.

Os adolescentes representam, no Brasil, $20,78 \%$ da população total, segundo o Censo Demográfico de 2000 (http:/ / www.ibge.gov.br). Constituem uma parcela da população predominantemente sadia e os dados mostram que mais de 50,0\% da mortalidade verificada entre eles, no Brasil, em Minas Gerais e nas cidades 
pesquisadas, se deve a causas externas (DATASUS: http://www.saude.gov.br), entre elas eventos violentos, em sua maioria associados ao uso de álcool e de outras drogas. Vários estudos no Brasil mostram a alta prevalência de comportamento de risco à saúde 1,2,3,4; muitos apontam também para a associação entre os vários riscos, por exemplo, entre o uso de álcool e tabaco e entre o comportamento sexual de risco e uso de drogas 3,5,6.

No mundo, a situação não é muito diferente. Considera-se que, atualmente, o maior objetivo das políticas de saúde nos Estados Unidos seja aumentar o percentual de adolescentes a chegar à vida adulta sem ter sido usuário de tabaco, álcool e drogas ilícitas 7. O Sistema de Vigilância de Comportamento de Riscos da Juventude revelou que, nos Estados Unidos, $16,8 \%$ relataram hábito de fumar, $26,7 \%$, uso de maconha, 31,5\% consumiam álcool e 36,3\% já tinham atividade sexual 7. O National Survey of Sexual Attitudes and Lifestyles mostra uma ampla variabilidade no estilo de vida sexual, por idade, gênero, estado civil e local de residência e um aumento da prevalência dos comportamentos sexuais de risco 5 . A associação entre os riscos também é verificada 3,5,6.

Nossa hipótese era a de que encontraríamos condições iguais ou piores nos espaços aqui estudados. As evidências obtidas no dia a dia do trabalho indicavam uma situação explosiva: inúmeros casos de gravidez adolescente, prostituição, amplo uso de álcool e de drogas ilícitas, uma crescente violência social, inclusive com a formação de "gangues" agindo à luz do dia. Os primeiros resultados, parciais, desse trabalho, desenvolvido, até então, nas cidades de Ibiaí e de Morada Nova de Minas e no Aglomerado Urbano Morro das Pedras confirmam, em parte, essa primeira impressão: são importantes e significativos os dados referentes aos adolescentes no que diz respeito à sua sexualidade, à sua inserção no trabalho, ao seu convívio com a violência (social e doméstica), às suas condições de vida e de acesso a serviços. Por outro lado, revelam novas situações, como a importância do contexto e dos processos interativos na interpretação, significação e apropriação de mensagens e informações recebidas pelos adolescentes, em que pese a ampla globalização e expansão dos meios de comunicação de massa, que os colonizam. Chama a atenção também a facilidade de mobilização e, na mesma medida, de desmobilização dos adolescentes. Um elemento importante, detectado nos três lugares é a existência de analfabetismo entre alunos que freqüentam a escola. Nas cidades de Morada Nova e de Ibiaí, detectamos um contraste entre a forte ressonância de algumas questões e o número modesto de casos encontrados, em especial, a drogadição e a gravidez adolescente. No Morro das Pedras, destaca-se a difusão da violência física para todos os espaços sociais e a substituição, por ela, de outros mecanismos interativos.

Essa pesquisa foi aprovada pelo Comitê de Ética da Universidade Federal de Minas Gerais (UFMG) e todos os envolvidos assinaram termos de consentimento livre e esclarecido. Conta com uma aluna bolsista de iniciação científica (Programa Institucional de Bolsas de Iniciação Científica, Conselho Nacional de Desenvolvimento Científico e Tecnológico), com dois bolsistas da Pró-reitoria de Extensão (UFMG) e alunos da graduação em medicina voluntários.

\section{A teoria necessária}

O objeto dessa pesquisa, implicando referências aos diferentes modos de vida, com seus contextos, cultura, organizações e lealdades, pressupõe uma teoria da sociedade. Ponderando-se que o recorte desse objeto é determinado por demandas praticamente detectadas em experiências duradouras e participativas, é possível identificar qual é a teoria necessária: aquela que mesmo não desconhecendo a existência de âmbitos da sociedade cuja reprodução se faz segundo leis regulares que seguem seu curso de forma alheia aos interesses e motivos dos atores sociais envolvidos, não abre mão de afirmar a necessidade de elementos normativos próprios de uma ordem social ainda influenciada pela ação do homem, resguardando assim a sua vinculação com uma razão prática. Essa síntese - condições objetivas e condições subjetivas; previsibilidade e vontade; teoria e prática; necessidade e liberdade perpassa toda a obra de Marx e assume as mais variadas feições e as mais diferentes formas de articulação, pelos mais diferentes autores, seguidores ou opositores do marxismo. Adotaremos a proposta formulada por Habermas 8,9,10,11, segundo a qual a sociedade é constituída por "Mundo da Vida" e "Sistema": o primeiro referente ao âmbito das interações entre sujeitos mediadas pelo entendimento lingüístico às quais se dá o nome de ação comunicativa; o segundo, ao âmbito da sociedade auto-regulada, dentro da qual os indivíduos são elementos abstratos, meras partes de uma engrenagem, autonomizada das suas orientações e motivações.

Essa concepção de sociedade traz impor tante e inegociável conseqüência metodológica para a pesquisa social: o conhecimento da 
realidade social não pode se dar exclusivamente pela ótica do observador e exige a mudança para a atitude do participante, uma vez que o sentido e a interpretação que os atores sociais dão ao mundo com base no contexto simbólico dentro do qual vivem, isto é, do seu mundo da vida, só se apresentam ao pesquisador "de dentro", se ele estabelecer com os atores sociais, uma interação mediada pelo entendimento lingüístico. Logo, se ele reconhecer es ses atores sociais como sujeitos portadores de direitos, vontade e competências para agir e falar e com eles interagir 8,9,10,12. Essa concepção de sociedade traz também conseqüências do ponto de vista prático: de acordo com ela, a evolução social não pode ser considerada apenas do ponto de vista de aumento de complexidade dos sistemas e da competência técnica, mas também da racionalização do mundo da vida, em que gradientes de racionalidade - portanto, o aprendizado social - são obtidos à medida que as crenças, normas e valores passam pelo crivo da argumentação, cuja institucionalização, nas sociedades modernas, gera um modelo radical de democracia que não pode pres cindir do processo representativo, é verdade, mas vincula-o ao livre e amplo debate público protagonizado pelos movimentos sociais $8,11,13$. No nosso entendimento, esse processo - a práxis de autonomia política dos cidadãos na conquista dos seus direitos - constitui a base que gera o SUS e os princípios que lhe dão identidade - a universalidade, a eqüidade e a integralidade 14 .

Não é difícil visualizar a fecundidade dessa teoria capaz de articular a produção de conhecimentos e a mudança social, para um trabalho que lida com a adolescência, pelas características especiais que ela tem, relativas à sua definição, à sua historicidade e ao seu papel, presente e futuro, na sociedade.

\section{Metodologia}

O universo da pesquisa foi constituído por adolescentes de 10 a 19 anos que freqüentam as escolas públicas e particulares das cidades envolvidas. Em consonância com os pressupostos teórico-metodológicos e práticos centrais dessa abordagem, este trabalho teve como princípio a existência de processos interativos, garantidos por uma longa inserção naquelas realidades e pela vinculação da pesquisa às práticas de ensino e extensão, processos estes que produziram mobilização social, facilitando, conseqüentemente, o processo de coleta de dados, melhorando a sua validade e efetivando a participação real necessária para conectar a pesquisa a planos de ação concretos e a demandas prioritárias daquela realidade 15,16 . Vários procedimentos foram associados, abor dando os vários enfoques da realidade a ser estudada.

(a) Questionário semi-estruturado: auto-aplicável, anônimo, preenchido e depositado em urnas lacradas, com questões não numeradas e colocadas em ordens diferentes. Foi elaborado tendo como subsídios outros questionários $2,7,17,18,19$ e sofreu radical modificação pelo piloto, realizado na forma de entrevista com adolescentes de idades, escolas, turnos e cidades diferentes, sobre cada uma das questões, testando a compreensão que tinham das mesmas; novo piloto foi realizado após este trabalho. A amostra foi estatisticamente calculada, com 95\% de confiança, controlando-se o erro em $5 \%$, mas, por questões éticas - a possibilidade de rotulação/discriminação dos adolescentes em cidades pequenas - e de segurança - a violência em alguns dos espaços pesquisados -, aplicou-se o questionário a todos os adolescentes de todas as escolas dos locais da pesquisa, extraindo depois a amostra de 50,0\% do total, mantendo a seleção aleatória por cidades, escolas, turnos e idade.

(b) Observação participante: nesta técnica, o pesquisador se mantém dentro de uma situação social e, à medida que participa da vida dos atores aí envolvidos, colhe dados; na verdade, trata-se de uma relação recíproca observação / participação, dentro de um fino equilíbrio, em que se precisa evitar tanto o risco da absorção definitiva do observador pela realidade observada quanto o risco da perda do elemento participativo, essencial para a pesquisa qualitativa 12,20 . Esse procedimento foi realizado pelo acompanhamento e registro em diário de campo dos comportamentos, ritos, preferências, costumes, reações, falas, enfim, das mais diferentes manifestações dos adolescentes que participam das atividades dos projetos de extensão e dos estágios curriculares de integração docente-assistencial da UFMG, desenvolvidos nos locais estudados. Esses projetos atuam permanentemente e criam a condição necessária à pesquisa, uma vez que permitem ao pesquisador uma aproximação da realidade pesquisada, sem perder a distância, por não pertencerem a ela. Os adolescentes engajados nessas atividades são aqueles que freqüentam as escolas públicas das localidades envolvidas; para eventos maiores, como seminários, jogos, jornadas etc. todos são convidados; para eventos mais restri tos, como oficinas e grupos de discussão, são escolhidos, aleatoriamente, dois por faixa etá- 
ria, turma, turno, escola e localidade. Entrevistas intencionalmente escolhidas e grupos focais estão ainda em andamento. A análise dos dados foi feita com base na leitura minuciosa e na discussão das informações empíricas, à luz dos conhecimentos teóricos acerca do tema, seguindo os seguintes passos: organização de todo material levantado e distribuição de cópias a todos os pesquisadores; realização de leituras recorrentes e seleção dos elementos comuns e/ou mais freqüentes e também dos destoantes, considerados importantes; discussão entre os pesquisadores - em alguns momentos, utilizamos, nessas discussões, as técnicas de grupos focais, pois elas ajudam a sistematização dos conteúdos; confrontação com a base teórica do projeto; nova discussão e, pela síntese desse processo, a definição das categorias: (1) a importância do mundo da vida e dos processos interativos para o adolescente e a partir daí (2) os riscos, especialmente, e (3) a violência.

\section{Análise e discussão dos resultados}

Apresentamos aqui, os resultados parciais obtidos até o momento, referentes ao questionário auto-aplicável e à observação participante, em Morada Nova e Ibiaí, e à observação participante, no Morro das Pedras.

\section{- Análise quantitativa dos dados obtidos pelo questionário: Morada Nova e Ibiaí}

Foram analisados 752 questionários (506 para a faixa etária de 10-14 anos e 244 para a faixa etária de 15-19 anos) referentes a uma amostra organizada segundo cidade, escola, turno e idade. Os questionários para a faixa etária de 1519 anos continham 112 perguntas, desdobradas em 197 variáveis; para a faixa etária de 1014 suas perguntas e variáveis foram reduzidas para 60 e 70, respectivamente. Algumas variáveis mostraram percentuais bastante expressivos: $51,7 \%$ dos adolescentes de $15-19$ anos relataram vida sexual ativa; $47,0 \%$ trabalham; $50,0 \%$ tiveram pelo menos uma reprovação na escola; $36,1 \%$ relatam o uso de álcool; $17,6 \%$ são vítimas de violência doméstica e 15,4\% agressão na rua; $14,6 \%$ de racismo $3,7 \%$ de estupro; $4,6 \%$ de abuso sexual; $25,4 \%$ relatam terem sido sujeitos de agressão física. Entre os adolescentes de 10-14 anos, destacamos: 32,6\% relatam agressão; 30,3\% trabalham; 20,3\% relatam uso de álcool; 18,0\% têm vida sexual ativa; $12,7 \%$ são vítimas de violência doméstica; e 38,5\% “ficam". Além desses índices que mostram a exposição dos adolescentes ao risco, é importante ressaltar, para a faixa etária de 10-
14 anos, que a atividade sexual e a inserção no trabalho já podem ser constatadas em adolescentes de 10 anos e que, aos 15 anos, os índices já estão bem próximos aos da média da faixa etária de 15-19 anos (Tabela 1). Os dados referentes à drogadição e à gravidez adolescente encontrados foram muito abaixo dos esperados e da média nacional, apesar da intensa preocupação da população em geral com tais quesitos. A explicação mais plausível é a de que esses adolescentes estão fora da escola. Essa in formação gerou nova proposta de abordagem, em andamento, via Programa Saúde da Família.

Para a faixa etária de 15-19 anos, muitas variáveis mostraram diferença significativa entre as cidades de Ibiaí e Morada Nova, entre elas, as que se referem ao padrão de vida, o que, mesmo em se tratando de duas pequenas cidades, era esperado por ser muito diferente a economia dos dois municípios, Ibiaí sendo muito mais pobre, dispondo de pior infra-estrutura básica e pior rede de serviços. Os questionários de 10-14 anos não trazem informações dessa natureza. Em ambas as faixas etárias, a inser ção no trabalho mostrou diferença significativa, maior em Ibiaí, situação que corrobora a relação dos dados com o perfil econômico dos municípios. As demais diferenças significativas detectadas segundo a cidade são mostradas na Tabela 2. São importantes também para adolescentes de 15-19 anos as diferenças entre os sexos, sendo os índices maiores para o sexo masculino. Mais exuberantes são as associações estatisticamente significativas entre os sexos, para os adolescentes da faixa etária de 1014 anos (Tabela 3). Entre os adolescentes de 15-19 anos foram encontradas associações es tatisticamente significativas, poucas no sentido de proteger e a maioria de expor os adolescentes aos riscos de saúde: participação em grupos religiosos se associa com menor atividade sexual ( $p=0,004)$; morar com os pais com menor prostituição ( $\mathrm{p}=0,028)$; abuso sexual se associa com atividade sexual ( $\mathrm{p}=0,043)$, com prostituição ( $\mathrm{p}=0,001)$ e homossexualismo $(0,000)$; alcoolismo com transar, ficar e namorar. Mas, entre os adolescentes de 10-14 anos, as associações são muito mais expressivas. Trabalhar se associa com a grande maioria dos fatores de risco - violência doméstica, agressão, abuso sexual, estupro, prostituição, homossexualismo, uso de cigarro; também se associa com namorar, "ficar" e "transar". O mesmo ocorre com violência doméstica, que se associa com violência na rua, acidente de trabalho, estupro, prostituição, homossexualismo, consumo de cigarro, trabalho. Vida sexual ativa se associa com uso de bebida alcoólica e cigarro; 
homossexualismo, acidente de trabalho, estupro, violência doméstica, agressão, abuso sexual. As variáveis relativas aos aspectos econômicos, políticos, sociais e culturais, para a faixa etária de 15-19 anos que mostraram correlação estatisticamente significativa com os riscos detectados estão apresentados na Tabela 4, merecendo destaque a associação de várias delas com o uso de álcool. A variável renda familiar não foi considerada porque a maioria dos adolescentes não conseguiu responder. Para a faixa etária de 10-14 anos, considerou-se apenas a inserção no trabalho, visto que as demais variáveis não foram perguntadas.

\section{Análise qualitativa}

É óbvia a importância do contexto e dos processos interativos que nele se desenrolam na formação dos adolescentes, no seu comportamento, no seu lidar com as suas aspirações e necessidades. Não poderia ser diferente. $\mathrm{O}$ adolescente é um sujeito e, como qualquer outro, compartilha com outros atores sociais, um mundo da vida que empresta sentido ao seu mundo e validade aos seus saberes. A formação da sua personalidade e da sua identidade se dá por intermédio do aprendizado e da interiorização de saberes e normas e vivências que lhes são repassados no convívio com os demais: o seu processo de individuação acontece simultaneamente e em decorrência da sua socialização 8,21. Vimos que o adolescente, tanto de Morro das Pedras quanto de Morada Nova e de Ibiaí, sente muita necessidade da fala e, embora tímido, sutilmente vai abrindo o espaço para se manifestar e influenciar nas situações - a interação com o outro é vital para ele e, apesar do seu bem conhecido caráter grupal, a nossa experiência tem mostrado que ele gosta e precisa do contato com diferentes pessoas, de diferentes idades e é possível vê-los por longas horas, junto delas, apenas conversando. Estudos mostram que o estabelecimento de pelo menos um vínculo social adequado pode protegê-lo de comportamentos desviantes $22 \mathrm{e}$, certamente não é casual o fato de que uma das suas principais queixas seja a de não serem ouvidos: “ $a$ gente tá sentado o dia todo é chato, ele [professor] virado para o quadro. A escola não discute o que a gente pede... a gente não tem liberdade para fazer perguntas pessoais..." (Adolescente de Morada Nova). "Professor folgado é o que mais detesto... professor folgado é aquele que só dá sermão... nada pode... e nem ouve o que a gente fala" (Adolescente do Morro das Pedras).

Decorrência dessa necessidade interativa é a capacidade de mobilização do adolescente.
Tabela 1

Atividade sexual e inserção no trabalho por idade.

\begin{tabular}{|c|c|c|c|c|c|c|c|c|}
\hline \multirow{2}{*}{$\begin{array}{l}\text { Idade } \\
\text { (em anos) }\end{array}$} & \multicolumn{4}{|c|}{ Atividade sexual } & \multicolumn{4}{|c|}{ Trabalho } \\
\hline & Sim & $\%$ & Não & $\%$ & Sim & $\%$ & Não & $\%$ \\
\hline 10 & 6 & 7,3 & 76 & 92,7 & 24 & 29,8 & 58 & 70,7 \\
\hline 11 & 9 & 9,3 & 88 & 90,7 & 26 & 26,8 & 71 & 73,2 \\
\hline 12 & 15 & 13,3 & 98 & 86,7 & 33 & 29,5 & 79 & 70,5 \\
\hline 13 & 26 & 22,8 & 88 & 77,2 & 38 & 32,8 & 78 & 67,2 \\
\hline 14 & 33 & 37,9 & 54 & 62,1 & 28 & 31,8 & 60 & 68,2 \\
\hline 15 & 29 & 36,3 & 51 & 63,7 & 32 & 40,0 & 48 & 60,0 \\
\hline 16 & 24 & 50,0 & 24 & 50,0 & 22 & 48,9 & 23 & 57,1 \\
\hline 17 & 30 & 55,6 & 24 & 44,4 & 22 & 40,7 & 32 & 59,3 \\
\hline 18 & 23 & 62,2 & 14 & 37,8 & 22 & 59,5 & 15 & 40,5 \\
\hline 19 & 17 & 89,5 & 2 & 10,5 & 12 & 66,7 & 6 & 33,3 \\
\hline
\end{tabular}

Tabela 2

Variáveis organizadas segundo a cidade.

\begin{tabular}{lrrrrr}
\hline Variáveis & Morada Nova & \multicolumn{2}{c}{ Ibiaí } & p \\
& $n$ & $\%$ & $n$ & $\%$ & \\
\hline Faixa etária de 15 a 19 anos & & & & & \\
Casa com esgoto & 92 & 86,0 & 80 & 62,0 & $<0,005$ \\
Com coleta de lixo & 100 & 91,7 & 88 & 66,2 & $<0,005$ \\
Com água encanada & 106 & 99,1 & 114 & 91,2 & 0,006 \\
Consumo de cigarros & 2 & 1,9 & 13 & 9,8 & 0,005 \\
Vítimas de estupro & 1 & 1,0 & 7 & 6,0 & 0,046 \\
Ficar & 76 & 75,2 & 66 & 55,0 & 0,001 \\
Transar & 70 & 64,2 & 55 & 41,7 & $<0,005$ \\
Namorar & 60 & 56,1 & 96 & 73,3 & 0,004 \\
Trabalho & 40 & 40,2 & 70 & 53,8 & 0,025 \\
Participação de grupos & 35 & 31,8 & 61 & 45,5 & 0,001 \\
& & & & & \\
Faixa etária de 10 a 14 anos & & & & & \\
Trabalho & 55 & 26,1 & 98 & 33,6 & 0,044 \\
Ficar & 112 & 53,3 & 73 & 14,7 & $<0,005$ \\
Morar com os pais & 201 & 95,7 & 265 & 90,7 & 0,026 \\
\hline & & & & &
\end{tabular}

Se você o convida, ele participa e investe. "Eu vou ficar nesse projeto até o fim" (Adolescente do Morro das Pedras). Às vezes, o processo de mobilização é tão intenso que chega a incomodar determinados setores da sociedade, que passam a se opor ao movimento. A sexualidade é um dos temas que mais mobiliza e, mesmo quando não está sendo abordado, perpassa todas as atividades, em todos os momentos: "teve algumas coisas do questionário que não entendi, mas respondi assim mesmo. Foi o maior co- 
Tabela 3

Variáveis organizadas segundo o sexo.

\begin{tabular}{|c|c|c|c|c|c|}
\hline \multirow[t]{2}{*}{ Variáveis } & \multicolumn{2}{|c|}{ Masculino } & \multicolumn{2}{|c|}{ Feminino } & \multirow[t]{2}{*}{$p$} \\
\hline & $n$ & $\%$ & $n$ & $\%$ & \\
\hline \multicolumn{6}{|l|}{ Faixa etária de 15 a 19 anos } \\
\hline Consumo de álcool & 52 & 46,0 & 35 & 27,3 & 0,003 \\
\hline Vítima de violência na rua & 27 & 24,1 & 10 & 7,8 & $<0,005$ \\
\hline Homossexualismo & 13 & 11,7 & 7 & 3,2 & 0,001 \\
\hline Transar & 85 & 74,6 & 40 & 31,5 & $<0,005$ \\
\hline Namorar & 67 & 59,8 & 88 & 70,4 & $<0,005$ \\
\hline Trabalhar & 61 & 54,5 & 51 & 41,1 & 0,041 \\
\hline Acidentes de trabalho & 41 & 36,6 & 14 & 11,2 & $<0,005$ \\
\hline \multicolumn{6}{|l|}{ Faixa etária de 10 a 14 anos } \\
\hline Vítima de violência na rua & 52 & 24,4 & 29 & 10,5 & $<0,005$ \\
\hline Vítima de agressão & 97 & 45,1 & 63 & 22,7 & $<0,005$ \\
\hline Vítima de abuso sexual & 3 & 1,4 & 12 & 4,3 & 0,049 \\
\hline Trabalhar & 89 & 40,6 & 60 & 21,7 & $<0,005$ \\
\hline Namorar & 67 & 31,5 & 16 & 17,3 & $<0,005$ \\
\hline Ficar & 107 & 51,0 & 76 & 28,7 & $<0,005$ \\
\hline Transar & 73 & 33,8 & 14 & 16,1 & $<0,005$ \\
\hline Prostituição & 4 & 1,9 & 0 & 0,0 & 0,036 \\
\hline Homossexualismo & 15 & 7,1 & 2 & 0,7 & $<0,005$ \\
\hline
\end{tabular}

mentário àquelas perguntas de sexo!" (Adolescente de Morada Nova). E, se por um lado, esse comportamento se relaciona com as mudanças culturais de contextos mais amplos, de maneira especial, a liberalização em relação às vivências de ordem sexual, a definição de um novo papel para a mulher, a separação entre a sexualidade e reprodução $23,24,25,26$, ele também é marcado pelo modo de viver concreto dos adolescentes - é notável a diferença entre os adolescentes do Morro das Pedras e os de Morada Nova e Ibiaí, os primeiros com um comportamento muito mais explícito, precoce e muitas vezes perverso, transparecendo nas expressões e gestos. A mesma coisa ocorre com a gravidez adolescente, encarada com naturalidade no Morro das Pedras: "lá em casa é assim, minha mãe... minha prima...todas pessoas que estão aqui tem gente que tá grávida..." (Adolescente do Morro das Pedras); e com receio em Morada Nova: “...quando eu ficar adulta eu já vou saber como que não fica grávida" (Adolescente de Morada Nova).

Sabe-se da associação entre qualidade de vida e riscos de saúde entre adolescentes 7. O Aglomerado Urbano Morro das Pedras localiza-se na região central de Belo Horizonte, com aproximadamente 20 mil habitantes; caracteriza-se por condições de vida muito precárias, com falta absoluta de acesso a bens e serviços elementares, entre eles a segurança: apresenta o maior índice de homicídio da grande Belo Horizonte. Morada Nova, uma pequena cidade às margens do Rio São Francisco, próxima à represa de Três Marias, desfruta de uma boa infra-estrutura de serviços e Ibiaí, do mesmo tamanho, também às margens do São Francisco, situa-se no norte de Minas e é muito pobre. Por mais que haja diferenças, em todas localidades constatou-se a existência de adolescentes cursando séries adiantadas; porém, analfabetos, e em nenhuma delas se detectaram iniciativas para lidar com a questão.

Ibiaí e Morada Nova mostram um impor tante índice de inserção precoce no trabalho, $33,6 \%$ e $26,1 \%$, respectivamente, para a faixa de 10-14 anos. Esses dados se mostram particularmente importantes quando vimos que a inserção no trabalho nessa faixa etária se associou a diversos riscos de saúde.

“Conversei também com um outro menino ...Ele me relatou que era a terceira vez que cursava a quinta série e que já estava cansando. Ele trabalha lavando carro e capinando e isso atrapalha os estudos..." (relato de conversa de um aluno da pesquisa com um Adolescente de Morada Nova)

"Eu vou cedinho com meu pai para a pesca...depois dá um sono...” (Adolescente de Ibiaí).

Não temos ainda os dados sobre a inserção dos adolescentes do Morro das Pedras no trabalho; percebe-se que problema para eles é, antes de tudo, a falta de trabalho e de oportunidades.

Um dos riscos mais presentes é a violência, especialmente grave em Morro das Pedras. Por mais de uma vez, ocorreram tiroteios, com morte de crianças; espancamento de um professor, dentro das escolas. Tão grave como a ocorrência desses eventos violentos é a constatação de que, mesmo no dia a dia, a lógica da força impera entre os adolescentes, constituindo, na opinião deles, o elemento mediador de todas as relações estabelecidas: "aqui no Morro, a gente não tem escolha, ou mata ou vai para debaixo da terra...", "medo de morrer a gente tem, mas fazer o quê?...". Desde a luta corporal que se trava ininterruptamente dentro e fora da classe, até a justificativa dada de que esse é o único e justo meio de resolver as questões, tudo sugere que esses comportamentos foram alçados à condição de regras legítimas, reconhecidas por todos como inevitáveis, impregnadas no jeito de viver de todos: "ele é bonzinho, não faz nada com ninguém... a não ser quando não pagam ele..." ou " na minha rua não tem problema não... só uns tiroteios”. 
Também em Morada Nova e Ibiaí foram detectadas demonstrações generalizadas de violência, nas suas mais variadas formas: a forte competição, a naturalidade da exclusão, a ridicularização das diferenças, a manipulação dos outros, a esperteza e até mesmo a agressão física. "Gostei muito dos jogos e até bati numa menina chata que ficou me atormentando, fiz dois galos na cabeça dela para ela aprender". Presenciamos a dura disputa na montagem dos times, a rejeição do colega no time sem a menor cerimônia, o uso da força física para soluções não desejadas, venda e falsificação de senhas, apelidos e brincadeiras com um adolescente homossexual; segregação e comentários indiscretos sobre supostos usuários de drogas ou outro comportamento de risco, como prostituição.

Quando se pensa no Morro das Pedras, é mais fácil entender a maciça reificação que ocorre em todos os espaços, tornando objetivos singelos quase inalcançáveis. Aí a realidade é muito mais dura e tanto a violência como a miséria e todos os riscos para saúde atingem um grau de intensidade e de explicitação muito grande, dominando o cotidiano dos adolescentes. Muitas crianças são vítimas de violência familiar, sofrem abuso sexual, usam drogas, se prostituem... Não deveria ser diferente em Morada Nova e em Ibiaí? Num trabalho realizado em Porto Alegre, Wagner et al. 27 descobriram que grande parte dos valores e crenças dos adolescentes e seus conseqüentes projetos de vida repetem aqueles das gerações anteriores, como na música de Belchior (Como Nossos Pais), também citada pelas autoras: “...minha dor é perceber que apesar de termos feito tudo que fizemos, ainda somos os mesmos e vivemos como nossos pais...". E eles, na sua maioria, querem ser felizes, ter uma boa casa, ter alguém para amar e se realizarem profissionalmente 27 . Não seria de esperar que lugares como Morada Nova e Ibiaí pudessem oferecer condições privilegiadas para a concretização desses objetivos? Não é o que se vê, no entanto: inclusive os momentos de lazer e de aprendizado são perpassados pela competição, pelo individualismo, pela violência nas suas mais variadas formas e pela necessidade de levar vantagem sobre os demais. E os adolescentes se sentem sozinhos, tristes, sem horizonte. "Já aproveitaram de mim... Sou revoltada... essa pesquisa é um jeito de desabafar.. de contar para alguém..." (Adolescente de Ibiaí; recado escrito no questionário). E ainda que disponham de certo grau de informações e apresentem potencialidades e tenham pelo menos o acesso mínimo necessário a certos bens, ainda assim, muitas das vezes, nem se dão conta disso, desvalorizam esses recur-
Tabela 4

Relações estatisticamente significativas para a faixa etária de 15-19 anos.

\begin{tabular}{|c|c|c|c|c|c|}
\hline Trabalha? & Sim & $\%$ & Não & $\%$ & $p$ \\
\hline \multicolumn{6}{|l|}{ Transa? } \\
\hline Sim & 65 & 58,0 & 57 & 46,3 & 0,048 \\
\hline Não & 47 & 42,0 & 66 & 53,7 & \\
\hline \multicolumn{6}{|l|}{ Homossexualismo? } \\
\hline Sim & 12 & 10,9 & 5 & 4,2 & 0,044 \\
\hline Não & 98 & 89,1 & 115 & 95,8 & \\
\hline Esgoto sanitário & $\begin{array}{l}\text { Com } \\
\text { esgoto }\end{array}$ & $\%$ & $\begin{array}{l}\text { Sem } \\
\text { esgoto }\end{array}$ & $\%$ & $p$ \\
\hline \multicolumn{6}{|l|}{ Fica? } \\
\hline Sim & 108 & 68,8 & 30 & 52,6 & 0,022 \\
\hline Não & 49 & 31,2 & 27 & 47,4 & \\
\hline \multicolumn{6}{|l|}{ Namora? } \\
\hline Sim & 106 & 62,7 & 46 & 75,4 & 0,049 \\
\hline Não & 63 & 37,3 & 15 & 24,6 & \\
\hline \multicolumn{6}{|l|}{ Consumo de álcool? } \\
\hline Sim & 52 & 30,4 & 32 & 50,8 & 0,003 \\
\hline Não & 119 & 69,6 & 31 & 49,2 & \\
\hline $\begin{array}{l}\text { Participação em } \\
\text { grupos religiosos }\end{array}$ & Sim & $\%$ & Não & $\%$ & $\mathrm{p}$ \\
\hline \multicolumn{6}{|l|}{ Transa? } \\
\hline Sim & 21 & 35,6 & 104 & 67,1 & 0,004 \\
\hline Não & 38 & 64,4 & 78 & 42,9 & \\
\hline Escolaridade & 1o grau & $\%$ & 2o grau & $\%$ & $\mathrm{p}$ \\
\hline \multicolumn{6}{|l|}{ Transa? } \\
\hline Sim & 32 & 41,0 & 92 & 57,5 & 0,012 \\
\hline Não & 46 & 59,0 & 68 & 42,5 & \\
\hline \multicolumn{6}{|l|}{ Fica? } \\
\hline $\operatorname{Sim}$ & 40 & 55,6 & 101 & 68,7 & 0,040 \\
\hline Não & 32 & 44,4 & 46 & 31,3 & \\
\hline \multicolumn{6}{|l|}{ Consumo de álcool? } \\
\hline Sim & 17 & 21,8 & 69 & 42,9 & 0,001 \\
\hline Não & 61 & 78,2 & 92 & 57,1 & \\
\hline Vítima de racismo & Sim & $\%$ & Não & $\%$ & $\mathrm{p}$ \\
\hline \multicolumn{6}{|c|}{ Vítima de violência doméstica? } \\
\hline Sim & 12 & 34,3 & 30 & 14,6 & 0,007 \\
\hline Não & 23 & 65,7 & 175 & 85,4 & \\
\hline \multicolumn{6}{|c|}{ Consumo de álcool? } \\
\hline Sim & 20 & 57,1 & 65 & 32,0 & 0,004 \\
\hline Não & 15 & 42,9 & 138 & 68,0 & \\
\hline \multicolumn{6}{|c|}{ Uso de drogas ilícitas? } \\
\hline Sim & 5 & 14,3 & 7 & 3,5 & 0,001 \\
\hline Não & 30 & 85,7 & 195 & 96,5 & \\
\hline \multicolumn{6}{|l|}{ Raça } \\
\hline Branca & 13 & 39,4 & 117 & 59,1 & 0,028 \\
\hline Negra/mestiça & 20 & 60,6 & 81 & 40,9 & \\
\hline
\end{tabular}


sos e não se responsabilizam pela sua preservação nem decifram neles possibilidades de gerar o novo. Num dos nossos encontros perguntamos sobre as atividades de lazer e a resposta foi unânime: “nada". Mas, pelo menos em Ibiaí e Morada Nova, eles nadam, andam a cavalo e de bicicleta, batem papo, praticam esporte... No Morro das Pedras, além de tudo, com freqüência eles se dizem "frutos podres do Morro...".

Habermas 28,29 descreve, entre as crises do capitalismo tardio, as crises de motivação e perda de sentido decorrentes da ruptura das tradições sem que outras sejam criadas, porque os elementos do mundo da vida como a cultura, a construção da identidade, da personalidade e das solidariedades só se reproduzem pelas interações entre sujeitos que se comunicam e estas cada vez mais são permeadas/destruídas/ substituídas por imperativos sistêmicos por meio da tecnologia, da linguagem codificada, do domínio dos meios de comunicação unidirecionais e massificadores, do uso do poder e do dinheiro, em todas as suas formas: a isso, o autor chama colonização do mundo da vida pelo sistema. $\mathrm{O}$ atual mundo globalizado que literalmente "entope" os adolescentes de informações técnicas, elimina o seu poder de influenciar e construir novos rumos, torna o mercado senhor absoluto de todas as coisas e com ele o individualismo, substituindo todas as demais referências, é o mundo onde nossos adolescentes são socializados. Nossa hipótese é a de que esse processo esteja relacionado e explique a disseminação da violência e dos demais riscos em espaços e realidades tão diferentes. E talvez possa explicar uma das nossas perplexidades, o fato de o adolescente ser tão bem informado e mesmo assim assumir determinados comportamentos de risco: é que a informação técnica, o dado, é externo a ele, não pertence ao seu mundo nem foi apropriado por ele, não pode nem sabe aplicá-lo.

Obviamente que com a tese da colonização do mundo da vida abrem-se também as possibilidades de sua superação: criar formas de sociabilidade, construir vínculos e investir nas interações em que sujeitos se reconhecem reciprocamente como portadores de saberes, de vontade, de direitos. Em muitas ocasiões, pudemos ter em Morada Nova, Ibiaí e Morro das Pedras a comprovação disso. Houve eventos que reuniram mais de mil adolescentes sem nenhum episódio de violência, de tumulto ou de destruição, por menor que fosse. Em uma das escolas do Morro das Pedras, a realização de um evento com mais de trezentos alunos, todos no pátio, com duração de mais de duas horas, imediatamente após o recreio - apelidado “terra de ninguém” por causa da desordem transcorreu alegremente, os adolescentes improvisando grupos de dança, de capoeira, de música. E num outro ainda, aberto à comunidade, mais de duzentos adolescentes, uns trinta de cada vez, ouviram o contador de estórias, refletiram, comentaram, criaram outras estórias... A nossa suposição para explicar esses comportamentos aparentemente contraditó rios é a de que tudo depende do grau de influência que cada um dos adolescentes pode ter na situação - até que ponto ele é sujeito no processo, mas segundo a avaliação que ele faz e pelas possibilidades que vislumbra de exercitar essa condição: "vocês vão ouvir a gente ou deixar a gente falando sozinho?” Quando refletem sobre as práticas de violência que vivenciam, a solução que apontam é a recuperação da sua condição de sujeitos: "vamos criar uma comissão de resgate e chegando aqui a gente pergunta para ele o que ele mais gostaria de discutir e fazer..." (proposta dos adolescentes de uma das oficinas). É possível perceber que gostariam de gerar novas regras capazes de inclusão, um novo jeito de viver: "quem usa droga vai poder participar?”. Essa é a aposta dos projetos de extensão da qual retiramos esses dados e, até nos momentos em que as relações ficam muito difíceis, quando temos de inter romper os trabalhos, eles insistem: “vocês vão voltar?”. Essa pergunta, repetida, insistente, renova os ânimos e tece o fio que permite a continuidade desse trabalho e, com ele, a chance de estabelecimento do vínculo necessário. E o jeito como é feita essa pergunta expressa uma promessa de acordo, uma certa tentativa de desculpar-se, mas sobretudo, um apelo: “não abandone a gente".

Por fim, um dos aspectos que chamou a atenção foi o fato de que muitos termos, palavras e expressões intensamente veiculados pela mídia e por profissionais das diferentes áreas foram entendidos pelos adolescentes e tomados pelos seus usos predominantes no contexto, muitas vezes, absolutamente diferentes dos que estavam sendo dados pelos pesquisadores. Expressões como "abuso sexual" foram entendidas por conta do seu uso rotineiro, que expressa traquinagem e desobediência aos pais; a expressão "ficar", tão badalada, era entendida no seu sentido mais forte, “ficar onde?”. Ou não eram entendidas: agressão física, freqüentemente, remuneração, enfim, termos que, na nossa avaliação, são relativamente simples, tiveram que ser traduzidos por exemplos concretos e experimentados. No dizer de Haber mas 13, mesmo a generalizada influência e controle dos meios de comunicação dependem de 
que se alcance o entendimento lingüístico com aqueles a quem se destinam, e aí é sempre possível dizer sim ou não.

\section{Conclusões}

A primeira e mais importante conclusão desse trabalho é a de que existem possibilidades de organização de práticas participativas junto aos adolescentes, em que eles sejam reconhecidos como sujeitos e de que elas são decisivas para a sua proteção contra os riscos aos quais estão expostos e para a produção da sua saúde. A relevância dessa constatação pode ser medida pelo fato de que os riscos de um modo ou de outro se associam à violência - quando designada em sentido amplo de negação do sujeito, englobando, dessa forma, o uso da força física, a imposição ao silêncio (violência simbólica) e, ainda, a negação de condições mínimas de vida, representada pela ausência de direitos civis, políticos e sociais 30 - violência que se manifesta nos mais diferentes espaços e, como mostra esse trabalho, tanto num aglomerado de uma grande metrópole como em pequeninas cidades do interior do Estado. Configurase, portanto, uma situação em que a necessidade de preservação do mundo da vida, imprescindível para a socialização, formação e construção de identidade dos adolescentes, enfim, para a produção de sujeitos, choca-se com a ameaça da sua colonização pelos mecanismos sistêmicos, num processo crescente de reificação. Não há caminhos alternativos so- brando. Ou bem se é devorado pelo curso próprio e intangível das coisas ou se insiste no fortalecimento e descompressão do mundo intersubjetivamente construído. Talvez, tão importante quanto produzir conhecimentos, nossas pesquisas devessem ter esse papel que poderia ser detonado por um gesto tão simples quanto o de levar os seus resultados para a discussão com aqueles que são os interessados mais imediatos. Gerando, é claro, novos conhecimentos e práticas. A confirmação empírica de que o mundo da vida - sua preservação ou sua deterioração - e as interações que os atores sociais aí tecem sejam decisivos para a proteção ou exposição ao risco constitui um resultado relevante e abre muitas possibilidades de investigação e de intervenção para problemas difíceis de serem abordados, demonstrando com isso a adequação metodológica da pesquisa e a coerência com o seu objetivo. Por outro lado, os resultados ainda são insuficientes para compreender, em profundidade, os elementos que compõem esse mundo, como eles operam na vida cotidiana e como os atores os incorporam e os transformam ao lidarem com questões tão candentes do seu dia a dia, os riscos, as opacidades, o sofrimento, a sociabilidade, o prazer, o desenvolvimento humano. Considerando, dentro desse horizonte, a continuidade dessa pesquisa, destaca-se a necessidade de apro fundar os estudos sobre a violência social entre jovens e adolescentes e de entender o seu comportamento em relação à sexualidade, à gravidez adolescente e ao uso de drogas.

\section{Resumo}

Este trabalho tem o objetivo de investigar os riscos de saúde em adolescentes de dois municípios do Vale do Rio São Francisco - Ibiaí e Morada Nova - e do Aglomerado Urbano Morro das Pedras, em Belo Horizonte. Articula-se ao trabalho de ensino e extensão voltado para a promoção de saúde do adolescente realizado pela Universidade Federal de Minas Gerais nessas localidades e utiliza como referencial teórico-metodológico primeiro a Teoria da Ação Comunicativa de Habermas. $\hat{E}$ um estudo qualitativo e quantitativo que utiliza a associação de vários procedimentos: aplicação de questionários nas escolas de ensino médio e fundamental, observação participante, grupos focais e entrevistas. Sexualidade, trabalho e violência apare- cem como os principais temas, associam-se a vários riscos, e sua importância se acentua com os altos percentuais encontrados, em adolescentes de ambas as faixas etárias abordadas, 10-14 e 15-19 anos. Entre os primeiros, o trabalho associa-se a quase todos os riscos. A relação entre o contexto e as práticas dos adolescentes, assim como as contradições detectadas entre elas, foram analisadas e interpretadas valendo-se da tese da colonização do mundo da vida, proposta por Habermas.

Adolescente; Promoção de Saúde; Comportamento do Adolescente 


\section{Colaboradores}

E. M. Melo foi responsável pelo desenho do estudo e participou da elaboração dos instrumentos, da redação do artigo, do trabalho de campo, da abordagem dos adolescentes, da análise e discussão dos dados e da confecção das tabelas. H. P. Faria participou da elaboração dos instrumentos e da construção do ban-

\section{Referências}

1. Tavares BF, Béria JU, Lima MS. Prevalência do uso de drogas e desempenho escolar entre adolescentes. Rev Saúde Pública 2001; 35:150-8.

2. Contrim-Carlini B, Gazal-Carvalho C, Gouveia N. Comportamentos de saúde entre jovens estudantes das redes pública e privada da área metropolitana do Estado de São Paulo. Rev Saúde Pública 2000; 34:636-45.

3. Scivolento S, Tsuji RK, Abdo CHN, Queiroz S, Andrade AG, Gattaz WF. Relação entre o consumo de drogas e o comportamento sexual de estudantes de 2 o grau de São Paulo. Rev Bras Psiquiatr 1999; 21:87-94.

4. Camacho LMY. As sutilezas das faces da violência nas práticas escolares de adolescentes. Educação e Pesquisa 2001; 27:123-40.

5. Johnson AM, Mercer CH, Erens B. Sexual behaviour in Britain: partnerships, practices, and HIV risk behaviours. Lancet 2001; 358:1835-42.

6. Ritchey PN, Reid GS, Hasse LA. The relative influence of smoking on drinking and drinking on smoking among high school students in a rural tobacco-growing county. J Adolesc Health 2001; 29:386-94

7. Topolski TD, Patrick DL, Edwards TC, Huebner CE, Connell FA, Mount KKJ. Quality of life and health-risk behaviors among adolescentes. J Adolesc Health 2001; 29:426-35.

8. Habermas J. Teoria de la acción comunicativa. Madrid: Tacurus; 1987.

9. Habermas J. Teoria de la acción comunicativa: complementos y estudios previos. Madrid: Cátedra; 1989.

10. Habermas J. Pensamento pós-metafísico. Rio de Janeiro: Tempo Brasileiro; 1990.

11. Habermas J. A nova intransparência. A crise do estado de bem-estar social e esgotamento das energias utópicas. Novos Estudos CEBRAP 1987; 18:103-14.

12. Minayo MCS. O desafio do conhecimento. 3a Ed. São Paulo: Editora Hucitec/Rio de Janeiro: ABRASCO; 1998.

13. Habermas J. Between facts and norms. Contributions to a discourse theory of law and democracy. Cambridge: The MIT Press; 1995.

14. Melo EM. Fundamentos para uma proposta democrática de saúde: a teoria da ação comunicativa de Habermas [Tese de Doutorado]. São Paulo: Faculdade de Medicina de Ribeirão Preto, Universidade de São Paulo; 1999.

15. Thiollent M. Metodologia da pesquisa-ação. 7ạ Ed. São Paulo: Cortez; 1996.

16. Brandão CR. Pesquisa participante. 5a Ed. São Paulo: Brasiliense; 1985. co de dados e das tabelas. M. A. M. Melo, A. B. Chaves e G. P. Machado contribuíram na elaboração dos instrumentos, no trabalho de campo, na abordagem dos adolescentes e na discussão dos resultados. G. P. Machado também contribuiu com a digitação dos dados.
17. Tótora PS. Perfil de saúde dos adolescentes de Maria da Fé [Monografia de Especialização]. Belo Horizonte: Curso de Especialização em Saúde da Família, Universidade Federal de Minas Gerais; 2000.

18. Secretaria Municipal de Saúde de Ibiaí. Diagnóstico municipal sócio-econômico e de saúde de Ibiaí. Ibiaí: Secretaria Municipal de Saúde de Ibiaí; 1999

19. Universidade Federal de Minas Gerais. Projeto Morada Nova. Belo Horizonte: Departamento de Medicina Preventiva e Social, Universidade Federal de Minas Gerais; 2000.

20. Morse JM. Innovative inquiry. Qual Health Res 2003; 13:447-8.

21. McCarthy T. The critical theory of Jürgen Habermas. 7th Ed. Cambridge/London: MIT Press; 1989.

22. Bru E, Murberg TA, Stephens P. Social support, negative events and pupil misbehaviour among young Norwegian adolescents. J Adolesc 2001; 24:715-27.

23. Souza RP. Sexualidade na adolescência. In: Maakaroum MF, organizador. Tratado de adolescência. Um estudo multidisciplinar. Rio de Janeiro: Editora Cultura Médica; 1991. p. 270-8.

24. Maakaroum MF. Considerações gerais sobre a adolescência. In: Maakaroum MF, organizador. Tratado de adolescência. Um estudo multidisciplinar. Rio de Janeiro: Editora Cultura Médica; 1991. p. 3-9.

25. Maakaroum MF. Violência e adolescência. In: Ética e cidadania. Anais do Seminário Ibero-americano de Adolescência. Belo Horizonte: Escritório de Histórias; 2000. p. 209-13.

26. Organização Mundial da Saúde/Fundo de População das Nações Unidas/Fundo das Nações Unidas para a Infância. Saúde reprodutiva de adolescentes: uma estratégia para ação. 2ạ Ed. Genebra: Organização Mundial da Saúde; 1989.

27. Wagner A, Falcke D, Meza EBD. Crenças e valores dos adolescentes acerca de família, casamento, separação e projetos de vida. Psicol Reflex Crit 1997; 10:155-67.

28. Habermas J. Técnica e ciência como ideologia. In: Os pensadores. v. LVIII. São Paulo: Abril Cultural; 1975.

29. Habermas J. Legitimation crisis. Boston: Beacon Press; 1975.

30. Zaluar A. Violência extra e intramuros. Revista Brasileira de Ciências Sociais 2001; 16:145-64.

Recebido em 02/Fev/2004

Versão final reapresentada em $07 / \mathrm{Jul} / 2004$

Aprovado em 22/Jul/2004 